\title{
Efecto de bacterias promotoras del crecimiento en la fertilización de la batata (Ipomoea batatas Lam)
}

\section{Effect of growth promoting bacteria on the fertilization of sweet potatoes (Ipomoea batatas Lam)}

\author{
Anthony R. Ariza-González ${ }^{1 \oplus}$; Alfredo DJ. Jarma-Orozco ${ }^{1 \oplus}$; \\ Jazmín V. Pérez-Pazos²®; Diana B. Sánchez-López²®
}

Recibido para publicación: Marzo 11 de 2019 - Aceptado para publicación: Mayo 24 de 2019

\begin{abstract}
RESUMEN
Una alternativa para disminuir el efecto de la fertilización química en los suelos y favorecer el crecimiento de los cultivos de batata es la incorporación de microorganismos promotores de crecimiento vegetal en la fertilización. En el Caribe Colombiano actualmente, la batata es uno de los cultivos emergentes debido a sus altas propiedades nutritivas en la dieta humana. El objetivo de este estudio fue evaluar el efecto de dos cepas bacterianas Pseudomonas denitrificans IBVS2 y Azotobacter vinelandii IBVS13 en el rendimiento de batata clon Tainung 66 en condiciones de campo, en el Valle del Sinú, Córdoba, Colombia. La investigación se desarrolló en segundo semestre del 2017, en el Centro de Investigación Turipaná-Agrosavia, utilizando esquejes apicales del clon Tainung 66, donde se implementó un diseño en bloques completos al azar con un arreglo factorial $3 \times 2+2$, evaluando variables del componente fisiológico, análisis químico foliar y edáfico, rendimiento y composición bromatológica. Los resultados mostraron que las variables rendimiento y masa seca radicular presentaron diferencias significativas con respecto al testigo químico cuando se implementó la fertilización empleando la cepa IBVS2 más 50\% del fertilizante químico, obteniendo un rendimiento de 11,32 t.ha- ${ }^{-1}$ y 5,78 t.ha- $^{-1}$ respectivamente. Estos resultados demuestran que la inoculación de PGPRs constituye una alternativa en el cultivo de batata, con efectos positivos al compararlo con la práctica de fertilización química completa.
\end{abstract}

Palabras clave: Nitrógeno; Pseudomonas denitrificans; Raíces tubérculos; Rendimiento.

${ }^{1}$ Facultad de Ciencias Agrícolas, Universidad de Córdoba, Montería, Córdoba, Colombia.

${ }^{2}$ Corporación Colombiana De Investigación AgropecuariaAgrosavia, Centro De Investigación Turipaná Montería, Córdoba, Colombia

*Autor para correspondencia: MSc. Diana Sánchez

Email: dbsanchez@agrosavia.co

\begin{abstract}
An alternative to reduce the effect of chemical fertilization on soils and favor the growth of sweet potato crops is the incorporation of microorganisms that promote plant growth in fertilization. In the Colombian Caribbean, sweet potato is currently one of the emerging crops due to its high nutritional properties in the human diet. The objective of this study was to evaluate the effect of two bacterial strains, Pseudomonas denitrificans IBVS2 and Azotobacter vinelandii IBVS13, on the yield of sweet potato clone Tainung 66 in field conditions, in the Valle del Sinú, Córdoba, Colombia. The research was carried out during second semester of 2017, at the Turipaná-Agrosavia Research Center, using apical cuttings from the Tainung 66 clone. A randomized complete block design with a $3 \times 2+2$ factorial arrangement was implemented, physiological component, foliar and edaphic chemical analysis, yield and bromatological composition variables were evaluated. The results showed that yield and dry root mass showed significant differences with respect to the chemical control when fertilization consisted of IBVS2 strain plus $50 \%$ of chemical fertilizer, obtaining a yield of 11.32 t.ha- $^{-1}$ and 5,78 t.ha- $^{1}$ respectively. These results showed that inoculation of PGPRs constitutes an alternative for sweet potatoes cultivation with positive effects when compared to complete chemical fertilization.
\end{abstract}

Key words: Nitrogen; Pseudomonas denitrificans; Tuber roots; Yield.

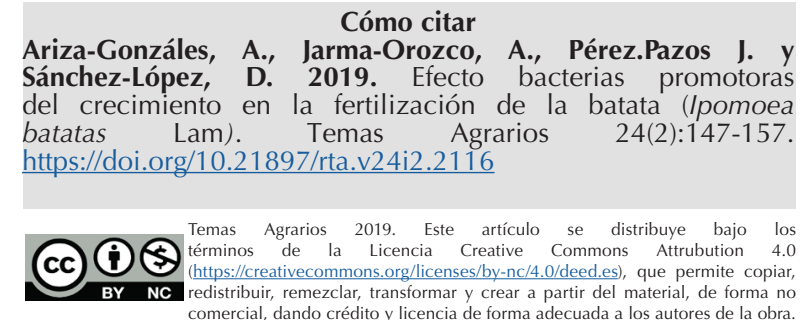

Temas Agrarios. Julio - Diciembre 2019; Vol. 24. No. 2, pp.147-157 | ISSNe 2389-9182 | https://doi.org/10.21897/rta.v24i2.2116 


\section{INTRODUCCIÓN}

La batata (Ipomoea batatas Lam.) es un alimento altamente energético, que contiene $25-30 \%$ de carbohidratos totales y es una fuente importante de carotenoides de provitamina A, vitamina C, potasio, hierro y calcio (Quiroga et al., 2016), situándolo como uno de los cultivos de importancia en la seguridad alimentaria a nivel mundial, después del arroz, trigo, maíz y yuca; se cultiva en 114 países, con una producción global aproximada de 113 millones de toneladas, siendo el continente asiático el mayor, con cifras que superan los 100 millones de toneladas equivalente al $82,5 \%$, donde se destaca China (FAOSTAT, 2017). En América Latina se destacan países productores como Brasil, Argentina, Perú, Haití y Cuba (Flórez et al., 2016). En Colombia, aunque el cultivo se realiza para consumo familiar y en ocasiones para la venta en mercados locales, la raíz tiene potencialidad para convertirse en una alternativa productiva y económica en la alimentación humana como producto fresco, la alimentaciónanimalcomoforrajeymateriaprima para la transformación industrial en comestibles, aditivos, almidones, alcoholes y otros derivados con valor agregado (Quiroga et al., 2016).

La producción de batata en el año 2012 fue de 626,8 toneladas, siendo el departamento de Sucre el de mayor volumen con una producción de 391 toneladas (62,38\%), otros departamentos que aportaron en la producción nacional fueron: Córdoba con 150 toneladas $(23,93 \%)$, Magdalena con 37,5 toneladas (5,98\%), Nariño con 29,2 toneladas $(4,65 \%)$ y el resto de la producción se distribuyó en las Islas de San Andrés y Providencia, con $14(2,23 \%)$ y $5,1 \quad(0,81 \%)$ toneladas, respectivamente (Flórez et al., 2016). La producción de batata en los departamentos de Sucre, Córdoba y Magdalena va en descenso, debido a la falta de interés por los productores, quizás influenciado por la baja demanda del producto en los mercados locales y al desconocimiento de las técnicas de producción, enfocadas a mejorar los rendimientos, con miras a la comercialización nacional e internacional (Flórez et al., 2016).

En Colombia, la batata se asocia a la red de productos de raíces y tubérculos, existiendo cultivares mejorados que están disponibles y que, a través de sus prácticas de manejo agronómico, tiene un potencial como materia prima y alternativo para las industrias procesadoras de alimentos balanceados para humanos y animales, gracias a que aporta un alto valor energético en las raíces tuberosas y un alto valor proteico en el follaje (Pedraza et al., 2015).

El uso de biofertilizantes representa una alternativa para limitar el uso de fertilizantes químicos, reduce el impacto ambiental y mejora la productividad de los cultivos. En este sentido, en Agrosavia se han desarrollado estudios en esta temática, en cultivos como tomate, lechuga, uchuva, pastos y ñame (Sánchez et al., 2012; Sánchez et al., 2014a; Sánchez et al., 2014b Sánchez et al., 2016; Sánchez et al., 2018). Por otra parte, los microorganismos fijadores de nitrógeno presentan ventajas frente al uso de fertilizantes químicos y favorecen a la preservación del medio ambiente y genera una agricultura sostenible (Dierksmeier, 2007).

Una de las alternativas al problema derivado de la fertilización es la aplicación de rizobacterias promotoras de crecimiento vegetal (PGPRs, por sus siglas en inglés) (Castillo et al., 2016). En el Centro de Investigación Turipaná de Agrosavia se adelantan investigaciones con microorganismos promisorios, disponiendo de una colección de bacterias pertenecientes a diferentes géneros entre los cuales se destacan Azotobacter, Azospirillum y Pseudomonas; los cuales fueron aislados de cultivos de batata en diferentes regiones del Caribe colombiano (Pérez y Sánchez, 2017). Esta investigación tuvo como objetivo evaluar el efecto de las cepas bacterianas Pseudomonas denitrificans IBVS2 y Azotobacter vinelandii IBVS13 en el rendimiento de la batata clon Tainung 66 en condiciones de campo. 


\section{MATERIALES Y MÉTODOS}

\section{Área de estudio}

La investigación se realizó en el segundo semestre del año 2017 en el Centro de Investigación Turipaná- Agrosavia, ubicado en el kilómetro 13 vía Montería-Cereté, Córdoba, Colombia, la zona presenta una altura de 14 msnm y las coordenadas geográficas son $8^{\circ} 50^{\prime} 79^{\prime \prime}$ de Latitud norte y $75^{\circ} 47^{\prime} 58^{\prime \prime}$ de Longitud oeste. Según Holdridge (1978), este pertenece a la zona de vida de bosque húmedo tropical (bh-T). Además, cuenta con las siguientes características climáticas de temperatura mínima $24{ }^{\circ} \mathrm{C}$, temperatura máxima $31{ }^{\circ} \mathrm{C}$ y temperatura promedio de 27,5 ${ }^{\circ} \mathrm{C}$, humedad relativa del $70 \%$ y precipitación anual de 1.340 mm/año (IDEAM, 2019).

\section{Microorganismos}

Las cepas que se emplearon fueron Pseudomonas denitrificans IBVS2 y Azotobacter vinelandii IBVS13 obtenidas en la investigación realizada por Pérez y Sánchez (2017), proporcionadas por el banco de trabajo del Laboratorio de Microbiología Agrícola del Centro de Investigación Turipaná - Agrosavia.

\section{Diseño experimental}

Cada parcela o unidad experimental (UE) constó de 5 surcos de 7,2 m de largo y una distancia de $1 \mathrm{~m}$ entre surcos para un total de $36 \mathrm{~m}^{2}$, la distancia entre parcelas fue de $2 \mathrm{~m}$ y $0,4 \mathrm{~m}$ entre plantas. El material vegetal que se utilizó fue esquejes de batata clon Tainung 66, completando un total de 2160 plantas en campo. Se utilizó un diseño de bloques completos al azar (DBCA) mediante arreglo factorial aumentado $3 \times 2+2$ de 8 tratamientos con 3 repeticiones, teniendo 24 unidades experimentales en total. El primer factor correspondió a las cepas bacterianas seleccionadas y caracterizadas a partir de cultivos de batata de la región Caribe, distribuidas en tres niveles: Pseudomonas denitrificans (IBVS2), Azotobacter vinelandii
(IBVS13) y mezcla; el segundo factor correspondió a la fertilización nitrogenada con dos niveles de 250 y 375 kg.ha- ${ }^{1}$ (50\% y $75 \%$ respectivamente); adicionalmente dos testigos sin inoculación con 0 y 500 kg.ha- ${ }^{1}$ fertilización nitrogenada (absoluto y químico respectivamente).

\section{Fertilización e inoculación}

Se incorporó Sulfato de Amonio (NH4) ${ }_{2} \mathrm{SO}_{4}$ como Fertilizante Nitrogenado (FN), según lo recomendado por el análisis de suelos, una cantidad total de 20 gramos/planta y se distribuyó al suelo al lado de la planta una primera fracción del 30\% a los 20 días después de la siembra (dds) y una segunda fracción del $70 \%$ a los 40 días después de la siembra (dds). Se hizo la inoculación bacteriana con $10 \mathrm{~mL}$ (concentración celular de $1 \times 10^{8}$ UFC. $\mathrm{mL}^{1}{ }^{1}$ ) medida con DO540=0,05 nm (TermoscientificGenesys $10 S$ UV-Vis) en medio Luria Bertani (LB) aplicando al pie de cada plántula de batata simultáneamente con la fertilización.

\section{Variables de respuestas}

Para determinar la variable de masa seca aérea se realizó con un marco de $50 \mathrm{~cm}$ x 50 cm y se lanzó aleatoriamente en cada unidad experimental (UE) o parcela, con el dato final del aforo se tomó el peso húmedo y peso seco, y se expresó en t.ha- ${ }^{1}$. La determinación de materia seca se realizó al momento de la cosecha (120 dds).

Los contenidos de N, P, K, Ca y Mg total en el tejido foliar se determinaron tomando 500 gramos de peso fresco foliar entre los tres surcos centrales en cada parcela. Esto se hizo a los 40 después de la siembra (dds), posteriormente, se Ilevaron al Laboratorio de química de suelos - Agrosavia para realizar el contenido foliar de nitrógeno (EPA 351,3 modificado), fósforo y potasio (Digestión abierta nítrico: perclórico (5:2) /Espectrometría de absorción atómica), calcio y magnesio (Digestión abierta nítrico: perclórico (5:2) /Espectrofotometría de 
emisión de plasma inductivamente acoplado) expresados en porcentaje (\%). El nitrógeno del suelo se determinó tomando muestras a una profundidad de $20 \mathrm{~cm}$ de $500 \mathrm{~g}$ de suelo por cada parcela, antes y después del experimento expresado en porcentaje (\%).

Para determinar la composición bromatológica de las raíces tuberosas se tomaron $500 \mathrm{~g}$ al momento de la cosecha (120 dds) por cada parcela, para determinar los contenidos de cenizas \% (AOAC 942.05), proteína \% (OAC 960.52), fibra cruda \% (NTC 5122), extracto etéreo \% (AOAC 2003.06; ICONTEC, 2002), la energía bruta y metabolizable los tubérculos se determinó utilizando una bomba calorimétrica (Parr 6200, Parr Instrument Company, Moline, IL).

Finalmente, se tuvo presente los datos de producción para rendimiento de raíces a los 120 días después de la siembra (dds). La recolección se hizo en los tres surcos centrales por cada parcela, para su determinación se incluyeron raíces primarias, secundarias, con o sin venas superficiales. Al momento de la cosecha, rendimiento y producción, y masa seca de raíces expresada en t.ha- ${ }^{1}$.

\section{Análisis estadístico}

Los datos fueron tabulados y organizados en Microsoft Excel office 2016 y Software SAS 9.4 (español); posteriormente sometidos a una evaluación estadística empleando un análisis de varianza y prueba de comparación de medias de Tukey $(\alpha \leq 0.05)$.

\section{RESULTADOS Y DISCUSIÓN}

Los cuadrados medios de varianza presentaron diferencias estadísticamente significativas $(\alpha \leq 0.05)$ de los factores cepa y fertilización, así como de su interacción entre el nitrógeno del suelo, masa seca de raíces y rendimiento total (Tabla 1).
Tabla 1. Cuadrados medios del análisis de varianza para la variable de nitrógeno del suelo, masa seca raíz y rendimiento total de raíces tuberosas del cultivo de batata clon Tainung 66.

\begin{tabular}{ccccc}
\hline Factor & G.L & $\begin{array}{c}\text { Nitrógeno } \\
\text { del suelo }\end{array}$ & $\begin{array}{c}\text { Masa } \\
\text { seca } \\
\text { radicular }\end{array}$ & Rendimiento \\
\hline Bloque & 2 & 0,0008 & 0,1206 & 2,3309 \\
Cepa & 3 & $0,0027^{*}$ & 0,0941 & 0,5209 \\
& & & & \\
Fertilización & 2 & 0,0002 & $1,0792^{*}$ & $14,4766^{*}$ \\
Cepa * & 2 & $0,0036^{*}$ & $1,2272^{*}$ & $18,7316^{*}$ \\
Fertilización & & & & \\
Error & 14 & 0,0006 & 0,0418 & 0,6976 \\
& & & & 10,07 \\
C.V & & 12,19 & 9,83 & \\
\hline
\end{tabular}

*Diferencias significativas $(\alpha \leq 0.05) ;$ G.L $=$ Grados de libertad; C.V. = coeficiente de variación

En nitrógeno del suelo, no hubo diferencias estadísticamente significativas entre los tratamientos frente a los testigos, pero se logra apreciar el mayor contenido de nitrógeno en el suelo cuando se inoculó P. denitrificans IBVS2+5\% FN (Tabla 2). Es difícil saber las cantidades reales de fertilización nitrogenada en asocio a las suspensiones bacterianas en batata de acuerdo con el material genético seleccionado. Por eso, aplicaciones de dosis nitrogenado inferiores o superiores al equilibrio nutricional, limitan la efectividad y beneficios de la inoculación tal como lo indica Espinosa et al., (2017).

La baja disponibilidad de nitrógeno disminuye las proteínas en los cloroplastos de las plantas y, por lo tanto, una degradación de su estructura podría afectar la capacidad fotosintética y ocasionando menores rendimientos, tanto de la parte aérea como para las raíces tuberosas (Barker y Pilbeam, 2015). Por consiguiente, todos estos factores como clima, suelo, clon y manejo agronómico 
interactúan entre sí y definen la demanda del nitrógeno para el cultivo, el suministro desde el suelo y la eficiencia de la fertilización en mezcla con las cepas bacterianas (Ferrera-Cerrato y Alarcón, 2004; Sandaña et al., 2012). En la masa seca aérea no se encontraron diferencias estadísticamente significativas entre los tratamientos
(Tabla 2). De igual forma, se presentan similitud a los encontrados por Pérez y Sánchez (2017) en donde evaluaron el efecto de microorganismos en plántulas de batata en invernadero, con las cepas A. vinelandii IBCB15 y Azotobacter sp. IBCB10 donde no presentaron diferencias estadísticamente significativas respecto a la masa seca aérea.

Tabla 2. Comparación de medias entre los factores cepa y fertilización para nitrógeno del suelo, masa seca aérea, masa seca raíz y rendimiento del cultivo de batata.

\begin{tabular}{lccccc}
\hline Cepa & Fertilización (\%) & NS (\%) & MSA (t.ha- ${ }^{\mathbf{1}}$ ) & MSR (t.ha- ${ }^{1}$ ) & RTO (t.ha- ${ }^{-}$) \\
\hline Sin inocular & 0 & $0,19 \pm 0,05 \mathrm{ab}$ & $0,55 \pm 0,01 \mathrm{a}$ & $2,48 \pm 0,16 \mathrm{ab}$ & $9,73 \pm 0,72 \mathrm{ab}$ \\
Sin inocular & 100 & $0,19 \pm 0,01 \mathrm{ab}$ & $0,69 \pm 0,22 \mathrm{a}$ & $1,40 \pm 0,12 \mathrm{e}$ & $5,78 \pm 0,83 \mathrm{~cd}$ \\
IBVS2 & 50 & $0,26 \pm 0,03 \mathrm{a}$ & $0,55 \pm 0,01 \mathrm{a}$ & $2,87 \pm 0,23 \mathrm{a}$ & $11,32 \pm 0,36 \mathrm{a}$ \\
IBVS2 & 75 & $0,19 \pm 0,01 \mathrm{ab}$ & $0,49 \pm 0,11 \mathrm{a}$ & $1,55 \pm 0,20 \mathrm{de}$ & $6,26 \pm 0,38 \mathrm{~cd}$ \\
IBVS13 & 50 & $0,18 \pm 0,01 \mathrm{~b}$ & $0,47 \pm 0,02 \mathrm{a}$ & $2,19 \pm 0,22 \mathrm{bc}$ & $8,39 \pm 1,29 \mathrm{bc}$ \\
IBVS13 & 75 & $0,20 \pm 0,01 \mathrm{ab}$ & $0,44 \pm 0,15 \mathrm{a}$ & $2,13 \pm 0,25 \mathrm{bcd}$ & $8,37 \pm 0,39 \mathrm{bcd}$ \\
IBVS2+IBVS13 & 50 & $0,22 \pm 0,01 \mathrm{ab}$ & $0,52 \pm 0,20 \mathrm{a}$ & $1,79 \pm 0,33 \mathrm{cde}$ & $7,35 \pm 1,53 \mathrm{~cd}$ \\
IBVS2+IBVS13 & 75 & $0,24 \pm 0,04 \mathrm{ab}$ & $0,53 \pm 0,15 \mathrm{a}$ & $2,23 \pm 0,24 \mathrm{bc}$ & $9,10 \pm 1,02 \mathrm{ab}$ \\
C.V & & 12,19 & 25,74 & 9,83 & 10,07 \\
\hline
\end{tabular}

*Medias con una letra en común no difieren estadísticamente según prueba de Tukey $(\alpha \leq 0.05)$; C.V. = coeficiente de variación; NS = Nitrógeno del suelo; MSA = Masa seca aérea; MSR = Masa seca raíz; RTO = Rendimiento.

Para la variable de masa seca de raíces se presentaron diferencias estadísticamente significativas $(\alpha \leq 0.05)$ en el tratamiento con P. denitrificans IBVS2+50\% FN en comparación con el testigo químico, pero no con el testigo absoluto (Tabla 2). El aumento de la biomasa seca está relacionado en la capacidad de las especies vegetales en la asimilación de una mayor cantidad de elementos minerales del suelo y que influyen de manera eficiente sobre el crecimiento y desarrollo, por consiguiente, es difícil saber las dosis de fertilización nitrogenada en asocio con bacterias PGPRs que permitan tener un mejor comportamiento en esta variable (Mujica-Pérez et al., 2017). Además, Mujica-Pérez et al. (2017) resaltaron el género Pseudomonas que tienen un potencial para estimular el crecimiento de las plantas por la producción de fitohormonas como la Auxina. Así mismo, estudios realizados por Buono y Ulla (2016), evidenciaron que la bacteria P. fluorescens estimuló la longitud radicular y peso seco en Tabaco (Nicotiana tabacum L.) y Pimiento (Capsicum annuum L.) donde se presentó similitud en los resultados obtenidos en este estudio en la variable de masa seca radicular con $\mathrm{P}$. denitrificans IBVS2+50\% FN que incrementó (52\%) respecto al testigo químico. De igual forma, Sánchez et al. (2019) evaluaron la respuesta a la incorporación de microorganismos y fertilización nitrogenada en la variable de materia seca radicular en el cultivo batata clon Tainung alcanzando con el tratamiento de testigo químico los valores más bajos materia seca radicular con un valor 
de 0,76 t.ha- ${ }^{1}$ y mostrando una similitud con nuestro estudio. En último lugar, para el rendimiento hubo diferencias estadísticamente significativas $(\alpha \leq 0.05)$ con la cepa $P$. denitrificans IBVS2+50\% FN en comparación con el testigo químico, pero no con el testigo absoluto (Tabla 2). Por lo tanto, estos resultados presentan similitud a los obtenidos por Ortiz y Flórez (2008), quienes afirman que, si bien el aporte del nitrógeno no afecta la inducción de la tuberización, una fertilización completa inhibe la formación de las raíces posterior a la inducción. Según los resultados alcanzados cuando se hizo $100 \%$ FN hubo la menor respuesta en rendimiento y masa seca de las raíces.

Por otro lado, resultados alcanzados por Huamán (2002) donde evaluó el rendimiento de tres clones de batata en cuatro niveles de fertilización nitrogenada sin la utilización de bacterias PGPRs, obtuvo con el clon SR 92.653.20 con niveles de nitrógeno de 100 kg.ha- ${ }^{1}$ y 50 kg.ha-1 el mayor rendimiento de raíces totales con 32,1 y 31,7 t.ha- ${ }^{1}$ respectivamente, siendo valores superiores a los alcanzados con el clon Tainung 66 a partir de todos los tratamientos. Adicionalmente, el clon Jewel con un nivel de nitrógeno de 150 kg.ha- ${ }^{1}$ en los caracteres de raíces totales obtuvo rendimientos 3,6 y 1,3 t.ha- $^{1}$ respectivamente, estos valores son inferiores al valor medio con Tainung 66 a partir del testigo químico, Huaman (2002) afirma que altas dosis de nitrógeno sin una adecuada disponibilidad de los demás elementos minerales provocó en la mayoría en los clones un desarrollo exuberante de la masa seca aérea, donde se presentó similitud con Tainung 66 con $100 \%$ FN.

Además, en una investigación reportado por Sánchez et al. (2019) sobre la respuesta a la incorporación de microorganismos y fertilización nitrogenada en el rendimiento del cultivo batata clon Tainung, en Corozal,
Colombia, obtuvieron con A. chroococcum IBCR19+75\% FN 12,18 t.h- ${ }^{1}$, superando al testigo absoluto y químico donde alcanzaron 6,95 y 3,18 t.ha- ${ }^{1}$, respectivamente, destacando con el testigo químico el menor rendimiento. Los rendimientos en los testigos absoluto y químico en este estudio fueron superiores a los reportados por los autores, sin embargo, muestra similitud con P. denitrificans IBVS2+50\% FN sobrepasando al testigo químico. Esto da a entender, que los valores de rendimiento, depende del clon y la eficiencia en la asimilación del nitrógeno, la localidad en donde se establezca el cultivo y manejo agronómico.

Para el contenido foliar de N, P, K, Ca y Mg, no se presentaron diferencias estadísticas significativas entre los tratamientos frente a los testigos controles (Tabla 3). Según Silva et al. (2016) y Cisneros-Rojas et al. (2017), las bacterias favorecen los contenidos de cada elemento, pudiéndose notar lo contrario en los contenidos de nitrógeno, fósforo, potasio, calcio y magnesio donde no hubo diferencia marcada. Además, estos microorganismos de vida libre pueden contribuir a la nutrición de las plantas a través de una variedad de mecanismos, incluidos los efectos directos sobre disponibilidad de nutrientes, por ejemplo, fijación de nitrógeno atmosférico $\left(\mathrm{N}_{2}\right)$, tal como lo indican Raaijmakers et al. (2009) y Martín et al. (2017), por el cual, no hay evidencias investigativas de suspensiones bacterianas sobre batata y el clon utilizado $u$ otros que permita explicar claramente el comportamiento del contenido foliar de nutrientes.

Además, las inoculaciones con estos microorganismos pueden afectar el follaje y contribuir directamente a la absorción de minerales por parte de la planta, en consecuencia, incrementan la biomasa y acumulación de minerales en el tallo y las hojas, donde en este estudio se presentó caso contrario cuando no se inoculó y hubo una fertilización nitrogenada completa. 
Tabla 3. Comparación de medias entre los factores cepa y fertilización para el contenido nutricional, foliar del cultivo de batata, clon Tainung 66 bajo condiciones de campo.

\begin{tabular}{|c|c|c|c|c|c|c|}
\hline Cepa & $\begin{array}{c}\text { Fertilización } \\
(\%)\end{array}$ & N (\%) & $\mathbf{P}(\%)$ & K (\%) & $\mathrm{Ca}(\%)$ & $\operatorname{Mg}(\%)$ \\
\hline Sin inocular & 0 & $4,61 \pm 0,21^{\mathrm{ab}}$ & $0,58 \pm 0,58^{a}$ & $5,73 \pm 0,82^{\mathrm{a}}$ & $0,60 \pm 0,10^{a}$ & $0,46 \pm 0,07^{\mathrm{a}}$ \\
\hline Sin inocular & 100 & $5,24 \pm 0,38 a b$ & $0,61 \pm 0,61^{\mathrm{a}}$ & $5,35 \pm 0,91^{\mathrm{a}}$ & $0,52 \pm 0,01^{a}$ & $0.40 \pm 0,04$ a \\
\hline IBVS2 & 50 & $4,84 \pm 0,27$ ab & $0,60 \pm 0,59^{\text {a }}$ & $5.34 \pm 0,80^{a}$ & $0,60 \pm 0,10^{a}$ & $0,42 \pm 0,02^{\mathrm{a}}$ \\
\hline IBVS2 & 75 & $4,71 \pm 0,9$ ab & $0,59 \pm 0,04^{a}$ & $5,37 \pm 0,47^{a}$ & $0,65 \pm 0,07^{a}$ & $0,49 \pm 0,03{ }^{a}$ \\
\hline IBVS13 & 50 & $5,44 \pm 0,37^{a}$ & $0,64 \pm 0,08^{a}$ & $5,25 \pm 1,04^{a}$ & $0,56 \pm 0,01^{a}$ & $0,45 \pm 0,03^{a}$ \\
\hline IBVS13 & 75 & $4,64 \pm 0,33$ ab & $0,61 \pm 0,02 a^{a}$ & $5,20 \pm 1,12^{a}$ & $0,69 \pm 0,07$ a & $0,41 \pm 0,06^{\mathrm{a}}$ \\
\hline IBVS2+IBVS13 & 50 & $4,53 \pm 0,34$ ab & $0,63 \pm 0,02^{a}$ & $4,86 \pm 0,70^{a}$ & $0,60 \pm 0,11^{a}$ & $0,47 \pm 0,09$ a \\
\hline IBVS2+IBVS13 & 75 & $4,35 \pm 0,40^{b}$ & $0,57 \pm 0,033^{a}$ & $4,75 \pm 0,16^{a}$ & $0,53 \pm 0,10^{a}$ & $0,41 \pm 0,04$ a \\
\hline C.V & & 7,23 & 7,71 & 14,78 & 11,99 & 12,47 \\
\hline
\end{tabular}

*Medias con una letra en común no difieren estadísticamente según prueba de Tukey $(\alpha \leq 0.05)$; C.V. = coeficiente de variación; $\mathrm{N}=$ Nitrógeno; $\mathrm{K}=$ Potasio; $\mathrm{P}=$ Fosforo; $\mathrm{Ca}=$ Calcio y Mg = Magnesio.

Los contenidos de nitrógeno, fósforo, potasio, calcio y magnesio el tejido foliar no presentó diferencias significativas entre los tratamientos para cada uno de los elementos minerales evaluados frente los testigos absoluto y químico. Por el contrario, en estudios realizados por Farzana y Radizah (2005), demostraron que tres aislados de rizobacterias incrementaron el crecimiento y la absorción de N, P, K, Ca y Mg en dos cultivares de batata, sin embargo, en nuestro estudio hubo un comportamiento estadístico similar entre los tratamientos y no se soporta con los resultados obtenidos por los autores.

Respecto a la composición bromatológica de las raíces tuberosas (Tabla 4), se encontraron diferencias estadísticas $(\alpha \leq 0.05)$ entre el testigo absoluto frente a A. vinelandii IBVS13+75\% $\mathrm{FN}$ en los contenidos de cenizas, siendo superior cuando no se inoculó ni fertilizó en comparación con la cepa A. vinelandii IBVS13. Seguidamente, en el contenido de fibra cruda hubo diferencias estadísticamente significati- vas $(\alpha \leq 0.05)$ cuándo se inoculó P. denitrificans IBVS2+75\% FN respecto al testigo absoluto y químico. Sin embargo, para los contenidos de proteínas, extracto etéreo, energía bruta y energía metabolizable, independientemente de los tratamientos evaluados, no hubo un comportamiento diferencial estadísticamente entre ellos en función de los testigos absoluto y químico. Estos contenidos fluctúan, de acuerdo con las características genéticas del cultivar, sistema de producción seleccionado (densidad de plantas, características de los suelos, etc.) y prácticas de manejo agronómico, siendo ideal aplicar las BPA (García et al., 2016).

Los contenidos de cenizas fueron similares a los encontrados por Sangronis et al. (2006), Yadav et al. (2006) y Martí et al. (2011) citado por García et al. (2016), quienes explicaron que este componente siempre se encuentra en una baja cantidades en la mayoría de las raíces y tubérculos, aunque estos valores obtenidos son altos (González et al., 2015). 
Tabla 4. Comparación de medias entre los factores cepa y fertilización para la composición bromatológica de las raíces tuberosas del cultivo de batata clon Tainung 66.

\begin{tabular}{|c|c|c|c|c|c|c|c|}
\hline Cepa & FER (\%) & CEN (\%) & PRO (\%) & EXTE (\%) & FC (\%) & EB & EM \\
\hline Sin inocular & 0 & $8,12 \pm 1,09^{a}$ & $13,34 \pm 0,90^{\mathrm{a}}$ & $0,65 \pm 0,16^{a b c}$ & $12,11 \pm 2,05^{b}$ & $3,93 \pm 0,20^{a}$ & $2,84 \pm 0,24^{a}$ \\
\hline Sin inocular & 100 & $6,35 \pm 0,43^{a b}$ & $13,24 \pm 0,17^{\mathrm{a}}$ & $0,43 \pm 0,09 a b c$ & $12,05 \pm 0,45^{b}$ & $4,05 \pm 0,21^{\mathrm{a}}$ & $2,99 \pm 0,24^{a}$ \\
\hline IBVS2 & 50 & $6.36 \pm 0,48^{\mathrm{ab}}$ & $12,35 \pm 1,46^{a}$ & $0,82 \pm 0,21^{a}$ & $13,71 \pm 2,06^{a b}$ & $4,21 \pm 0,14^{\mathrm{a}}$ & $3,18 \pm 0,16^{a}$ \\
\hline IBVS2 & 75 & $7,07 \pm 0,61$ ab & $14,24 \pm 2,97^{\mathrm{a}}$ & $0,70 \pm 0,28{ }^{a b}$ & $18,70 \pm 1,62^{a}$ & $4,22 \pm 0,22^{\mathrm{a}}$ & $3,19 \pm 0,26^{a}$ \\
\hline IBVS13 & 50 & $6,16 \pm 0,22 \mathrm{ab}$ & $13,79 \pm 1,84 \mathrm{a}$ & $0,40 \pm 0,15 \mathrm{abc}$ & $14,67 \pm 2,53^{a b}$ & $4,07 \pm 0,08^{\mathrm{a}}$ & $3,01 \pm 0,09^{a}$ \\
\hline IBVS13 & 75 & $5,64 \pm 0,45^{b}$ & $14,84 \pm 1,09^{a}$ & $0,36 \pm 0,07 \mathrm{bc}$ & $13,41 \pm 1,64^{a b}$ & $3,98 \pm 0,15^{\mathrm{a}}$ & $2,90 \pm 0,17^{\mathrm{a}}$ \\
\hline IBVS2+IBVS13 & 50 & $6,15 \pm 0,70^{\mathrm{ab}}$ & $14,24 \pm 0,69^{a}$ & $0,23 \pm 0,10^{c}$ & $11,32 \pm 1,37^{b}$ & $4,08 \pm 0,01^{a}$ & $2,99 \pm 0,04^{\mathrm{a}}$ \\
\hline IBVS2+IBVS13 & 75 & $7,20 \pm 1,08^{a b}$ & $14,08 \pm 1,37^{a}$ & $0,47 \pm 0,17 \mathrm{abc}$ & $11,52 \pm 2,98^{b}$ & $3,91 \pm 0,10^{\mathrm{a}}$ & $2,82 \pm 0,11^{\mathrm{a}}$ \\
\hline C.V & & 11,08 & 11,24 & 30,65 & 15,23 & 3,98 & 6,58 \\
\hline
\end{tabular}

*Medias con una letra en común no difieren estadísticamente según prueba de Tukey $(\alpha \leq 0.05)$; C.V. $=$ coeficiente de variación; FER = Fertilización; CEN = Cenizas; $\mathrm{PRO}=$ Proteína; $\mathrm{EXTE}=$ Extracto etéreo; $\mathrm{FC}=$ Fibra cruda; $\mathrm{EB}=$ Energía bruta y $\mathrm{EM}=$ Energía metabolizable expresado en $\mathrm{Kcal} / \mathrm{kg} / \mathrm{MS}$.

Por otro lado, los contenidos de proteínas fueron considerados altos y dentro del intervaloreportadoporvariosautores, queseñalan promedios entre 3,73 a 10,01 g/100 g para algunas especies de raíces y tubérculos, aunque hayan diferido estadísticamente entre los tratamientos (Yépez y Estévez, 2014) siendolascantidades en esteestudiosuperioresal rango máximo de proteínas (Serrano et al., 2011; Puerta, 2012). Sin embargo, los contenidos de cenizas, proteínas, fibra cruda, extracto etéreo, energía bruta y metabolizable se ven afectados o mejorados por efecto de las características genéticas del clon, condiciones edafoclimáticas de la región, entre otros factores asociados a la domesticación de la especie (Techeira et al., 2014; García et al., 2016; ).

Resultados encontrados por Rodas (2008) donde evaluó el efecto de Azospirillum sp. sobre caracteres agronómicos y rendimiento en trigo duro variedad Jupare, encontró incremento en el contenido de proteína, extracto etéreo, fibra cruda y energía metabolizable en el grano a partir de la inoculación bacteriana respecto al testigo absoluto, esto puede explicarse que quizás estos valores de los contenidos mencionados anteriormente pueden encontrarse en el rango máximo, aun así con diferencias estadísticas entre los tratamientos, por lo cual no hay reporte de estudios relacionados con PGPRs sobre la batata. Finalmente, se conoce el potencial que tienen las bacterias PGPRs en las plantas, permitiendo mejorar la composición nutricional y calidad de las raíces tuberosas, fundamentales para la dieta humana como un alimento sano y nutritivo, que estas dependerán del material genético (clon), condiciones edafoclimáticas y el manejo agronómico. 


\section{CONCLUSIONES}

La cepa P. denitrificans IBVS2+50\% FN promovió la capacidad del crecimiento vegetal en la batata clon Tainung 66, incrementando el rendimiento y masa seca radicular en relación con el testigo químico, bajo condiciones de campo. El uso de biofertilizante a base de esta cepa bacteriana sería una estrategia fundamental en la nutrición y desarrollo del cultivo batata aumentado su productividad y ayudando a una sostenibilidad ambiental.

\section{Conflicto de Intereses}

Los autores declaran que es un trabajo orginal y no existío conflicto de intereses de ningún tipo en la elaboración y publicación del manuscrito.

\section{AGRADECIMIENTOS}

Este estudio fue financiado por el Ministerio de Agricultura y Desarrollo Rural Colombiano bajo el convenio número TV17 con Agrosavia, Laboratorio de Microbiología Agrícola del Centro de Investigación Turipaná. Este trabajo formó parte del proyecto" Desarrollo y vinculación de tecnologías para sistemas de producción de ñame y batata para consumo fresco, transformación y exportación en el Caribe Colombiano", que hace parte de la agenda de la investigación de Agrosavia.

\section{REFERENCIAS}

AOAC (Association of Official Analytical Chemists). 2016. Official methods of analysis of AOAC International. 20th ed. AOAC Int., Gaithersburg, MD, USA

Barker, A. y Pilbeam, D. 2015. Handbook of Plant Nutrition. Florida, US: CRC Press. p 613.
Buono, N. y Ulla, E. 2016. Efectos de la inoculación con bacterias solubilizadoras de fosfato en tabaco (Nicotiana tabacum L.) y pimiento (Capsicum annuum L.) en condiciones controladas. Revista agronómica del noroeste argentino, 36(2): 45-54.

Castillo, C., Huenchuleo, M., Michaud, A. y Solano, J. 2016. Micorrización en un cultivo de papa adicionado del biofertilizante Twin- $\mathrm{N}$ establecido en un Andisol de la Región de La Araucanía. Idesia (Arica), 34(1): 39-45.

Cisneros-Rojas, C., Sánchez-de Prager, $M$. y Menjivar-Flores, J. 2017. Efecto de bacterias solubilizadoras de fosfatos sobre el desarrollo de plántulas de café. Agronomía Mesoamericana, 28(1): 149158.

Dierksmeier, G. 2007. Origen y desarrollo del análisis de residuos de plaguicidas en Cuba. Fitosanidad, 11(3): 87-90.

Espinosa, B., Moreno, A., Cano, P., Álvarez, V., Sáenz, J., Sánchez, H. y González, G. 2017. Inoculación de rizobacterias promotoras del crecimiento vegetal en tomate (Solanum lycopersicum L.) Cv. afrodita en invernadero. Terra Latinoamericana, 35(2): 169-178.

Farzana, Y. and Radizah, O. 2005. Influence of Rhizobacterial Inoculation on Growth of the Sweetpotato Cultivar. Journal of Biological Sciences, 1(3): 176-179.

Ferrera-Cerrato, R. y Alarcón, A. 2004. Biotecnología de los hongos micorrízicos arbusculares. In: Memoria Simposio de Biofertilización (eds). Río Bravo, Tampa, México. p 1-9.

Flórez, D., Contreras, C. y Uribe, C. 2016. Perspectivas Tecnológica y comercial para el cultivo de batata en Colombia. Mosquera: Centro de publicación Corporación Colombiana de Investigación Agropecuaria (CORPOICA). p 70. 
FAOSTAT-Organización para las naciones unidad para alimentación y agricultura FAO. 2017. Organización de las Naciones Unidas para la Agricultura y la Alimentación. Statistics databases. Base de datos disponibles

http://www.fao.org/faostat/en/?\#data/QC/ visualize

García, A., Pérez, M., Méndez, A. y Madriz, P. 2016. Caracterización postcosecha y composición química de la batata (Ipomoea batatas (L.) Lam.) variedad Topera. Agronomía Mesoamericana, 27(2): 287-300.

González, A., Alvis, A. y Arrázola, G. 2015. Efecto del Recubrimiento Comestible en las Propiedades de Trozos de Batata (Ipomoea batatas Lam) Fritos por Inmersión: Parte 1: Textura. Información tecnológica, 26(1): 95-102.

ICONTEC (Instituto Colombiano de Normas Técnicas y Certificación). 2002. Norma técnica colombiana NTC 5122: Alimentos para animales. Determinación del contenido de fibra cruda. Método con filtrado intermedio. ICONTEC, COL

Holdridge, R. 1978. Ecología basada en zonas de vida. San José: Instituto Interamericano de Cooperación para la Agricultura (IICA). Capítulo 2. El diagrama de las zonas de vida. p 13-28.

Huamán, A. 2002. Rendimiento de tres clones de camote (Ipomoea batatas Lam.) en cuatro niveles de fertilización nitrogenada en Tulumayo. Tesis de pregrado, Universidad Nacional Agraria de la Selva, Tingo Maria, Perú. p 99.

IDEAM. 2019. Boletín agroclimático a nivel nacional (Colombia). [Fecha de consulta: mayo 29 mayo 2019].

http://www.ideam.gov.co/web/tiempo-yclima/boletin-agroclimatico

Martí, H., Corbino, G. y Chludil, H. 2011. La batata. El redescubrimiento de un cultivo. Ciencia Hoy, 21(1): 17-23.
Martín, G., Tamayo, Y., Hernández, I., Varela, M. y Da Silva, E. 2017. Cuantificación de la fijación biológica de nitrógeno en Canavalia ensiformis crecida en un suelo pardo mullido carbonatado mediante los métodos de abundancia natural de $15 \mathrm{~N}$ y diferencia de $\mathrm{N}$ total. Cultivos Tropicales, 38(1): 122-130.

Mujica-Pérez, Y., Medina-Carmona, A. y Rodríguez-Guerra, E. 2017. Inoculación de hongos micorrízicos arbusculares y bacterias promotoras del crecimiento vegetal en el cultivo de maní (Arachis hypogaea L.). Cultivos Tropicales, 38(2): 15-21.

Ortiz, L. y Flórez, V. 2008. Comparación cuantitativa de ácido abscísico y citoquininas en la tuberización de Solanum tuberosum L. y Solanum phureja Juz. et Buk. Agronomía Colombiana, 26(1):32-38.

Pedraza, C., Flórez, D. y Uribe, C. 2015. Perspectivas tecnológicas y comerciales para el cultivo de la batata (Ipomoea batatas Lam.) en Colombia.

Pérez, J. y Sánchez, D. 2017. Caracterización y efecto de Azotobacter, Azospirillum y Pseudomonas asociadas a Ipomoea batatas del Caribe Colombiano. Revista Colombiana de Biotecnología, 19(2): 3546.

Puerta, J. 2012. Desarrollo de una mezcla base para chips de batata. Tesis de grado, Universidad Simón Bolívar, Caracas, Venezuela. p 92.

Quiroga, M., Aguero, D., Zapata, R., Busilacchi, H. y Bueno, M. 2016. Activadores de crecimiento y biofertilizantes como alternativa al uso de fertilizantes químicos en cultivo de chía (Salvia hispanica L.). Energías Renovables y Medio Ambiente (ERMA). p 35.

Raaijmakers, J., Paulitz, T., Steinberg, C., Alabouvette, C. and Moënne, Y. 2009. The rhizosphere: a playground and battlefield for soilborne pathogens and beneficial microorganisms. Plant and soil, 321(1-2): 341-361. 
Rodas, J. 2008. Efectividad de biofertilizante, sobre caracteres agronómicos y rendimiento en trigo duro variedad Jupare. Tesis pregrado, Universidad Autónoma Agraria Antonio Narro, Buenavista, México. p 49.

Sánchez López, D., Gómez-Vargas, R., Garrido Rubiano, F. y Bonilla Buitrago, R. 2012. Inoculación con bacterias promotoras de crecimiento vegetal en tomate bajo condiciones de invernadero. Revista mexicana de ciencias agrícolas, 3(7):1401-1415

Sánchez, D., Hoyos, M., Perdomo, A. y Buitrago, R. 2014a. Efecto de rizobacterias promotoras de crecimiento vegetal solubilizadoras de fosfato en Lactuca sativa cultivar White Boston. Revista Colombiana de Biotecnología, 16 (2):122- 128 .

Sánchez, D., Romero, F. y Bonilla, R. 2014b. Respuesta de Physalis peruviana L. a la inoculación con bacterias solubilizadoras de fosfato. Revista mexicana de ciencias agrícolas, 5(5): 901-906.

Sánchez, D., Pérez, J. y Hinestroza, D. 2016. Efecto de las PGPB sobre el crecimiento Pennisetum clandestinum bajo condiciones de estrés salino. Revista Colombiana de Biotecnología, 18(1): 6572.

Sánchez, D, Pérez, J., Luna, L., García, J. y Espitia, A. 2018. Evaluación de Azotobacter vinelandii y Pseudomonas denitrificans en Dioscorea rotundata en condiciones de campo. Fave. Sección ciencias agrarias, 17(1): 35-43.

Sánchez, D., Pérez, J., Luna, L., García, J. y Espitia, A. 2019. Azotobacter chroococcum y Azospirillum lipoferum como bioestimulantes en cultivo de Ipomoea batatas Lam. Agronomía Mesoamericana, 30(2): 563-576.
Serrano, A., Vílchez, C., Sandino, S., Carrillo, P. y Pachón, H. 2011. Evaluación sensorial de tortas de camote (Ipomoea batatas), elaboradas con o sin hojas de camote, con niños en edad escolar en Nicaragua. Revista Perspectivas Nutricionales Humana, 13(1): 191-202.

Sandaña, P., Santos, J., Orena, S. y Kalazich, J. 2012. Fertilización Nitrogenada para el cultivo de papa en la zona centro-sur de CHILE. Instituto de Investigaciones Agropecuarias (INIA), Ministerio de la Agricultura, Chile. p 4.

Sangronis, E., Teixeira, P., Otero, M., Guerra, M. y Hidalgo, G. 2006. Manaca, batata y ñame: posibles sustitutos del trigo en alimentos para dos etnias del Amazonas venezolano. ALAN, 56(1): 122-128.

Silva, C., de Mello, R., Castellanos, L., Abreu, M. y Rosatto, L. 2016. Fuentes de fosfato asociadas a la cachaza y el biofertilizante sobre los microorganismos solubilizadores de fósforo y su contenido en el suelo. Cultivos Tropicales, 37(1): 22-27.

Techeira, N., Sivolí, L., Perdomo, B., Ramírez, A. y Sosa, A. 2014. Caracterización fisicoquímica, funcional y nutricional de harinas crudas obtenidas a partir de diferentes variedades de yuca (Manihot esculenta Crantz), batata (Ipomoea batatas Lam) y ñame (Dioscorea alata), cultivadas en Venezuela. INTERCIENCIA, 39(1): 191-197.

Yadav, A., Guha, M., Tharanathan, R. y Ramteke, S. 2006. Cambios en las características de las harinas de camote preparadas por las diferentes técnicas de secado. JFST, 39(1): 20-26.

Yépez, L. y Estévez, N. 2014. Determinación de las características físicas y químicas del camote (Ipomea batata) de la variedad de pulpa morada. Tesis de grado, Universidad Técnica del Norte, Ecuador. p 95. 